\title{
Interaction between chloramphenicol and acetaminophen
}

\author{
J S SPIKA, D J DAVIS, S R MARTIN, K BEHARRY, J REX, AND J V ARANDA \\ Department of Pediatrics, McGill University, and Montreal Children's Hospital, Montreal, Quebec, Canada
}

SUMmARY Acetaminophen has been reported either to prolong or not to affect the clearance of chloramphenicol. To confirm one of these findings we studied the clearance of chloramphenicol and its metabolites using high pressure liquid chromatography in five patients (ages 2.5 to 5 years) before and during oral treatment with acetaminophen $(50 \mathrm{mg} / \mathrm{kg} / \mathrm{day})$. Significant differences were observed in mean (SD) peak serum chloramphenicol concentration $(-9 \cdot 7(3 \cdot 2)$ $\mathrm{mg} / \mathrm{l})$, mean (SD) apparent volume of distribution $(+225(162) \mathrm{ml} / \mathrm{kg})$, mean (SD) chloramphenicol half life $(-1.9(1 \cdot 1)$ hours $)$, mean (SD) chloramphenicol clearance $(+236(94) \mathrm{ml} / \mathrm{kg} / \mathrm{h})$, mean (SD) area under the curve $(-83.5(33.0) \mathrm{mg} / \mathrm{l} / \mathrm{h})$, and mean (SD) elimination constant $\left(+0 \cdot 34(0 \cdot 13) \mathrm{h}^{-1}\right)$ between samples obtained before and during treatment with acetaminophen. Acetaminophen, when given orally for several days, increased the clearance of chloramphenicol, perhaps by increased glucuronidation. This report re-emphasises the need for therapeutic drug monitoring whenever these two drugs are used together.

Haemophilus influenzae is the leading cause of bacterial sepsis and meningitis in children between the ages of 1 month and 5 years. ${ }^{1}$ Chloramphenicol is a first line antibiotic for the treatment of invasive disease caused by ampicillin resistant $H$. influenzae. ${ }^{2}$ Often these children have an increased temperature and are given antifever treatment. It has been reported that acetaminophen given intravenously prolongs the serum half life of chloramphenicol in adults. ${ }^{3}$ Recently, Kearns et al observed no differences in the pharmacokinetics of chloramphenicol between patients who received acetaminophen orally and those who did not when these groups were compared after the first dose of chloramphenicol and from the seventh through the seventeenth doses. ${ }^{4}$ Interestingly, they found that clearance of chloramphenicol significantly increased in those children who received acetaminophen between the steady state period and the final dose. The pharmacokinetics of chloramphenicol are extremely variable. ${ }^{5}$ The inability of Kearns $e t$ al to detect differences between their two treatment groups may have been due to the design of their study. To clarify questions raised by these reports, we looked at the effect of oral acetaminophen on the clearance of chloramphenicol in subjects who served as their own controls.

\section{Patients and methods}

Five patients admitted to the Montreal Children's Hospital between December 1983 and November 1984 who had positive blood cultures for $H$. influen$z a e$ type b were studied. Their ages were $2 \cdot 5,2 \cdot 5$, $3 \cdot 5,4$, and 5 years. Four subjects had epiglottitis and one had meningitis. None had received acetaminophen for the illness for which they were subsequently admitted to hospital. All subjects were initially treated with intravenous chloramphenicol $80 \mathrm{mg} / \mathrm{kg} / \mathrm{day}$ and intravenous ampicillin 100-200 $\mathrm{mg} / \mathrm{kg} /$ day until the culture results were known and the ampicillin was stopped. One patient received two doses of rifampin during the 48 hours before the first kinetic study was performed. After 48-72 hours of treatment with chloramphenicol a 24 hour urine collection was obtained for a chloramphenicol clearance. During this collection period, a heparin lock was placed and after a dose of chloramphenicol had been infused over 20 minutes $1 \mathrm{ml}$ samples of blood were obtained 30 minutes and one, two, three, four, and six hours after the infusion was complete. The blood was allowed to clot, and the serum removed and stored at $-70^{\circ} \mathrm{C}$. At the completion of this 24 hour urine collection, oral acetaminophen $50 \mathrm{mg} /$ $\mathrm{kg} /$ day every six hours was started. Each dose of 
acetaminophen was given 30 minutes before an infusion of chloramphenicol.

Forty eight to 72 hours after the start of treatment with acetaminophen urine was again collected over 24 hours for chloramphenicol clearance and the subject's blood was sampled at the time points noted above after an intravenous dose of chloramphenicol. Serum specimens for each subject were run together as a batch.

Acetaminophen, chloramphenicol, and chloramphenicol succinate concentrations in serum and urine samples and chloramphenicol glucuronide concentrations in urine samples were determined using a modified high pressure liquid chromotography technique described by Aravind et al. ${ }^{6}$ In brief, $0.1 \mathrm{ml}$ sodium acetate buffer $\mathrm{pH} 4 \cdot 6(1.0 \mathrm{~N})$ and 1.0 $\mathrm{ml}$ ethyl acetate containing $20 \mu \mathrm{g} / \mathrm{ml}$ 5-ethyl-5-ptolybarbituric acid (ETBA) were added to $0.05 \mathrm{ml}$ spiked serum or patient's serum. After vortexing and centrifuging, the organic top layer was transferred to a clean tube and evaporated under air. The residue was resuspended in $0.05 \mathrm{ml}$ methanol and $0.02 \mathrm{ml}$ was injected into the column. Optimal resolution was achieved using a uBondapak $\mathrm{C} 18$ column with an eluent solution of methanol: water:acetic acid (37:62:1) over a period of 18 minutes with a flow rate of $1.5 \mathrm{ml} / \mathrm{min}$ at ambient temperature. Standard spiked solutions with ETBA as an internal standard were extracted according to the procedure outlined above. The average per cent recovery was $99 \%$.

The drug concentrations were calculated by integration of the area under the curve of the chromatographic peak by the trapezoidal method. The average retention times for chloramphenicol, chloramphenicol succinate, glucuronide (from urine samples), and acetaminophen were $5 \cdot 86,8 \cdot 5$, 5.76 , and 2.65 minutes, respectively. The coefficients of variance at 5,15 , and $25 \mathrm{mg} / \mathrm{l}$ of chloramphenicol were $5 \cdot 8,5 \cdot 6$, and $4 \cdot 7 \%$, respectively. Kinetic variables were analysed assuming a one compartment open model using areas under the time concentration curve (AUC) from 0 to infinity.

The serum concentrations of chloramphenicol and its metabolites were plotted semi-logarithmically. The elimination rate constant Kel and the serum half life $\left(t_{1 / 2}\right)$ were computed from the slope of the drug disappearance curve. This slope was determined by the method of least squares; extrapolation to time zero generated the computed chloramphenicol concentration at time zero $\left(\mathrm{Cp}_{\mathrm{o}}\right)$. The apparent volume of distribution ( $\mathrm{AVd}$ ) was calculated as dose/AUC/Kel. Chloramphenicol clearance $\left(\mathrm{CC}_{\mathrm{L}}\right)$ was computed as dose/AUC. Chloramphenicol concentrations in serum and kinetic variables obtained before treatment with acetaminophen were compared with those obtained during treatment with acetaminophen using the $t$ test for paired samples and Wilcoxon's matched pairs signed rank test. $^{7}$

The protocol and consent form used in this study were approved by the Montreal Children's Hospital ethics committee. Consent was obtained from the parent and patient (if possible) before enrolment.

\section{Results}

Significant differences in $\mathrm{Cp}_{\mathrm{O}}, \mathrm{AVd}, \mathrm{t}_{1 / 2}, \mathrm{CC}_{\mathrm{L}}$, AUC, and Kel occurred between samples obtained before and during treatment with acetaminophen (Table 1). This change was greatest for $\mathrm{CC}_{\mathrm{L}}$, which

Table 1 Chloramphenicol kinetic variables before and during treatment with acetaminophen for the five patients. Values are mean (SD)

\begin{tabular}{lccl}
\hline \multirow{2}{*}{ Kinetic variable } & \multicolumn{2}{l}{ Treatment with acetaminophen } & \multirow{2}{*}{ p Value* } \\
\cline { 2 - 3 } & Before & During & \\
\hline $\mathrm{CP}_{\mathrm{O}}(\mathrm{mg} / \mathrm{l})$ & $26 \cdot 7(5 \cdot 7)$ & $17 \cdot 0(4 \cdot 9)$ & $<0 \cdot 003$ \\
$\mathrm{AVd}(\mathrm{ml} / \mathrm{kg})$ & $306(78)$ & $531(202)$ & $<0 \cdot 04$ \\
$\mathrm{Kel}\left(\mathrm{h}^{-1}\right)$ & $0 \cdot 26(0 \cdot 09)$ & $0 \cdot 60(0 \cdot 15)$ & $<0 \cdot 004$ \\
$\mathrm{t}_{1 / 2}(\mathrm{~h})$ & $3 \cdot 0(1 \cdot 3)$ & $1 \cdot 2(0 \cdot 3)$ & $=0 \cdot 02$ \\
$\mathrm{AUC}(\mathrm{mg} / \mathrm{l} / \mathrm{h})$ & $112 \cdot 2(42 \cdot 6)$ & $28 \cdot 7(12 \cdot 2)$ & $=0 \cdot 005$ \\
$\mathrm{CC}(\mathrm{ml} / \mathrm{kg} / \mathrm{h})$ & $78(23)$ & $314(107)$ & $<0 \cdot 005$ \\
\hline
\end{tabular}

$\mathrm{CP}_{\mathrm{O}}=$ Computed chloramphenicol concentration at time zero; $\mathrm{AVd}=$ apparent volume of distribution; $\mathrm{Kel}=$ elimination rate constant: $\mathrm{t}_{1 / 2}=$ serum half life; $A U C=$ area under the time concentration curve from 0 to $\alpha ; C_{L}=$ chloramphenicol clearance.

${ }^{*} t$ Test for paired samples, two tailed; $\mathrm{p}=\mathbf{0 . 0 4}$ for all variables by Wilcoxon's matched pairs signed rank test, two tailed.

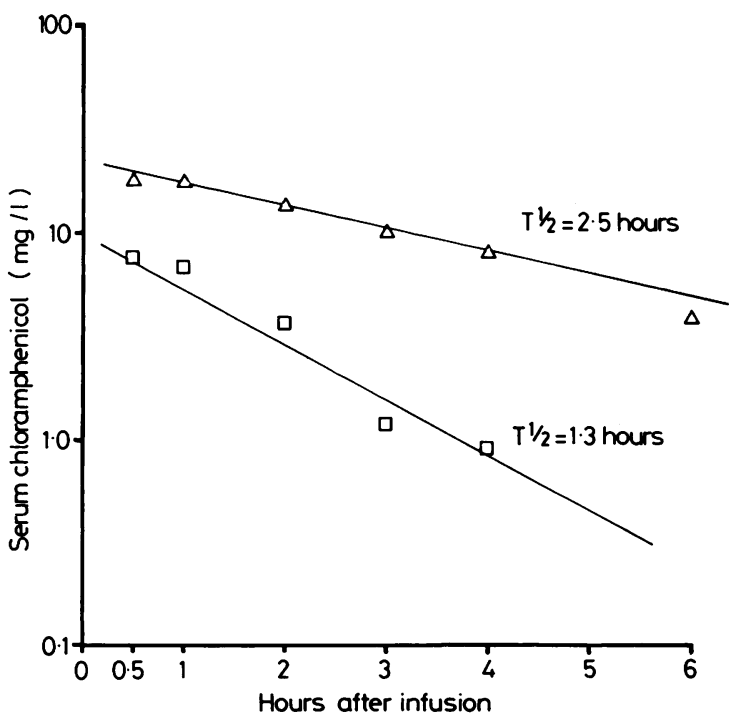

Figure Chloramphenicol kinetics in the serum of a patient before $(\triangle)$ and during $(\square)$ treatment with acetaminophen. 
Table 2 Urinary excretion of chloramphenicol and metabolites by the five patients before and during treatment with acetaminophen. Values are mean (SD) percentage of chloramphenicol $(\mathrm{mg} / \mathrm{l})$ excreted in the urine as chloramphenicol, chloramphenicol succinate, and chloramphenicol glucuronide

\begin{tabular}{llc}
\hline Compound excreted & \multicolumn{2}{l}{ Treatment with acetaminophen } \\
\cline { 2 - 3 } & Before & During \\
\hline Chloramphenicol & $27 \cdot 4(5 \cdot 9)$ & $17 \cdot 7(6 \cdot 2)^{*}$ \\
Chloramphenicol succinate & $69 \cdot 1(5 \cdot 9)$ & $72 \cdot 2(12 \cdot 9)$ \\
Chloramphenicol glucuronide & $3 \cdot 5(2 \cdot 0)$ & $10 \cdot 1(11 \cdot 6)$ \\
\hline
\end{tabular}

${ }^{*} \mathrm{p}<0.05$ Compared with before treatment with acetaminophen, $t$ test for paired samples, two tailed; $p=0 \cdot 04$. Wilcoxin's matched pairs signed rank test. two tailed.

increased to a mean (SD) of $236(94) \mathrm{ml} / \mathrm{kg} / \mathrm{h}$ (a $303 \%$ increase from the level before treatment with acetaminophen). A representative serum disappearance curve in one patient is presented in the Figure. All patients recovered uneventfully, although one patient was unable to achieve a 30 minute peak chloramphenicol concentration in the $10-20 \mathrm{mg} / \mathrm{l}$ range considered therapeutic.

The percentage of chloramphenicol excreted in the urine as chloramphenicol, chloramphenicol succinate, and chloramphenicol glucuronide before and during treatment with acetaminophen is shown in Table 2.

\section{Discussion}

Our results, showing a decrease in $\mathrm{CP}_{\mathrm{O}}$, AUC, and $t_{1 / 2}$ and an increase in $A V d, K e l$, and $\mathrm{CC}_{L}$ during treatment with acetaminophen, contrast to those previously published. These differences may be explained by differences in assay techniques and study design. Buchanan and Moodley described six adult patients who were given $1 \mathrm{~g}$ of chloramphenicol intravenously, after which their serum chloramphenicol concentrations were monitored for two hours. ${ }^{3}$ Acetaminophen $100 \mathrm{mg}$ intravenously was then given and additional serum samples for chioramphenicol were taken over the next four hours. Serum chloramphenicol concentrations were determined using a microbiological assay. Urinary excretion of chloramphenicol metabolites was not determined.

Acetaminophen is rapidly absorbed from the gastrointestinal tract after oral administration; $10-32 \%$ of the drug is lost through first pass metabolism by the liver and does not reach the systemic circulation. ${ }^{8}$ The drug is extensively metabolised, primarily by the liver. The major metabolite in adults is the glucuronide conjugate. ${ }^{2}$ The use of intravenous acetaminophen in adults could result in higher peak blood concentrations and perhaps contribute to decreased chloramphenicol metabolism by competition for glucuronyl transferase activity. As sulphate conjugation of acetaminophen is the predominate route of degradation in children ${ }^{9} 10$ a prolongation of the half life of chloramphenicol after a single intravenous infusion of acetaminophen may not be as pronounced.

The method used to determine chloramphenicol concentrations is another important difference between these studies. High pressure liquid chromatography is a highly sensitive and specific method. Buchanan and Moodley used a turbidimetric procedure, which measured inhibition of growth of Shigella sonnei. ${ }^{11}$ The mean chloramphenicol concentration in their patients after treatment with acetaminophen was $\leqslant 10 \mathrm{mg} / \mathrm{l}$. Microbiological methods, while measuring antimicrobial activity, are not specific for a particular drug. The patients in the earlier report had all received broad range antibiotics. What effect these other antibiotics may have had on the determination of chloramphenicol concentrations was not mentioned. A similar turbidimetric method had a sensitivity of $5-10 \mathrm{mg} / \mathrm{l}^{12}$ As the report by Buchanan and Moodley did not contain patients who received chloramphenicol alone we do not know whether the serum concentrations reported were a result of treatment with acetaminophen or whether their procedure did not allow for accurate determination of chloramphenicol concentrations at the time points after acetaminophen was given.

The report by Kearns and coworkers found no differences in chloramphenicol pharmacokinetics between 18 children who received acetaminophen and eight who did not during their admission to hospital $;{ }^{4} 10$ children treated with acetaminophen had received the drug before their admission. In addition, the selection process for those who received aspirin or no antifever drug was not clearly defined. Large differences exist in pharmacokinetic variables of chloramphenicol among normal subjects. The half life of chloramphenicol in paediatric patients has been reported to range between 1.7 and 12.0 hours. $^{5}$ To control for this extreme variability, it is important to use patients as their own controls whenever possible. The report by Kearns et al did find differences in pharmacokinetic variables between the first and last dose of chloramphenicol in those children who had not received acetaminophen before their admission to hospital and a significant increase in chloramphenicol clearance at the time of the last dose in those patients treated with acetaminophen. ${ }^{4}$ The methodological problems with these earlier reports highlight the problems with 
pharmacokinetic studies when appropriate controls are not used.

One of our patients received two doses of rifampin within 48 hours of the first kinetic study. This patient's pharmacokinetic variables for chloramphenicol were similar to those of the other patients who did not receive acetaminophen. Treatment with rifampin has been reported to increase metabolism of itself and other drugs, ${ }^{13-15}$ probably as a result of induction of drug metabolising enzymes as evidenced by a proliferation of smooth endoplasmic reticulum of the hepatocyte and increased glucuronidation. ${ }^{16}$ Such activation is usually maximal 48 hours after induction. If treatment with rifampin affected our patient's metabolism of chloramphenicol the effect should have been present before the first kinetic study. The recent report of an effect of rifampin on chloramphenicol concentrations used peak serum concentrations, which can be affected by rate of drug infusion, and did not specify whether the patients received acetaminophen before admission to hospital. ${ }^{17}$

The accelerated chloramphenicol clearance after treatment with acetaminophen could not be attributed to state of hydration or fever as these clinical states were similar for both study periods. Moreover, the most substantial change was noted in the elimination rate constant $(+131 \%)$, not $\mathrm{AVd}$ $(+74 \%)$. This indicates that the increase in chloramphenicol clearance is due mainly to an accelerated elimination rate constant secondary to increased metabolism. This is supported by an almost twofold increase in the urinary excretion of the glucuronide metabolite (Table 2).

Age, rate of infusion, obesity, underlying disease, and other drugs that the patient is receiving have all been shown to effect the serum concentration of antibiotics administered intravenously. This report re-emphasises the need for therapeutic drug monitoring whenever drugs with narrow therapeutic index are used and the drug therapeutic concentrations are near the presumed toxic concentrations.
${ }^{2}$ Leferriere CI, Marks MI. Chloramphenicol: properties and clinical use. Pediatr Infect Dis 1982;1:257-64.

${ }^{3}$ Buchanan N, Moodley GP. Interaction between chloramphenicol and paracetamol. Br Med J 1979;ii:307-8.

${ }^{4}$ Kearns GL, Bocchini JA, Brown RD, Cotter DL, Wilson JT. Absence of a pharmacokinetic interaction between chloramphenicol and acetaminophen in children. $J$ Pediatr 1985;107:134-9.

5 Kauffman RE, Miceli JN, Strebel L, Buckley JA, Done AK, Dajani AS. Pharmacokinetics of chloramphenicol and chloramphenicol succinate in infants and children. $J$ Pediatr 1981;98:315-20.

6 Aravind MK, Miceli JN, Kauffman RE, Strebel LE, Done AK. Simultaneous measurement of chloramphenicol and chloramphenicol succinate by high-performance liquid chromatography. J Chromatogr 1980;14:176-81.

7 Siegel S. Non-parametric statistics for the behavioral sciences. New York: McGraw-Hill, 1956.

${ }^{8}$ Forrest JAH, Clements JA, Prescott LF. Clinical pharmacokinetics of paracetamol. Clin Pharmacokinet 1982;7:93-107.

${ }^{9}$ Miller RP, Roberts RJ, Fischer LJ. Acetaminophen elimination kinetics in neonates, children and adults. Clin Pharmacol Ther 1976;19:284-94.

10 Alam SN, Roberts RJ, Fischer LJ. Age-related differences in salicylamide and acetaminophen conjugation in man. $J$ Pediatr 1977;90:130-5.

"Glazko AJ, Wolf LM, Dill WA, Bratton AC. Biochemical studies on chloramphenicol. J Pharmacol Exp Ther 1949; 96:445-59.

12 De Louvois J, Mulhall A, Hurley R. Comparison of methods available for assay of chloramphenicol in clinical specimens. J Clin Pathol 1980;33:575-80.

13 Acocella G, Smith R. Kinetic studies on the combination rifampicin-trimethoprim in man. I. Absorption and urinary excretion after administration to healthy volunteers of single doses of the two compounds alone and in combination, and the combination over a period of 1 week. J Antimicrob Chemother 1976;2:271-7.

${ }^{14}$ Kreek MJ, Garfield JW, Gutjahr CL, Giusti LM. Rifampininduced methadone withdrawal. N Engl J Med 1976;234:1104-6.

15 Herman RJ, Nakamura K, Wilkinson GR, Wood AJJ. Induction of propranolol metabolism by rifampicin. Br J Clin Pharmacol 1983;16:565-9.

16 Gianni A. Pharmacokinetics and metabolism of rifampin in humans. Rev Infect Dis 1983;5(suppl):428-32.

17 Prober CG. Effect of rifampin of chloramphenicol levels. N Engl J Med 1985;312:788-9.

Correspondence to Dr J V Aranda, Montreal Children's Hospital, 2300 Tupper Street, Montreal, Quebec, H3H1P3, Canada.

\section{References}

${ }^{1}$ Gold R. Bacterial meningitis-1982. Am J Med 1983;75:98-101. 